\title{
Climate change blamed for rise in hay fever
}

Rachael Williams, Tokyo

Spare a thought for Japan's myriad hay-fever sufferers as they endure the highest pollen levels on record this spring. Global warming seems at least partly to blame and most experts agree that the worst is yet to come.

Hay fever in Japan is more punishing than that triggered by weed pollen, which occurs in much of the rest of the world. It is caused by an allergic reaction to cedar and cypress pollen. Severe symptoms and the spread of pollen over wide distances is forcing thousands of people, even in urban areas, to don protective masks and glasses.

There are about 7 million hectares of cypress and cedar plantations in Japan. In Tokyo alone, about a quarter of the population is suffering from hay fever. And according to government surveys the number is steadily rising.

Kouji Murayama, a researcher at the Japan Meteorological Business Support Center in Tokyo, believes that the culprit is global warming. He points to studies that show a clear link between summer temperatures and the amount of pollen produced the following spring. Such data already provide the basis for pollen forecasts.

Tokyo's average yearly temperature has increased by $3^{\circ} \mathrm{C}$ since 1890 and, according to the Japan Meteorological Agency in Tokyo,
IMAGE

\section{UNAVAILABLE FOR COPYRIGHT REASONS}

Fever pitch: many Japanese need protective masks to help them fend off the effects of tree pollen.

is set to rise by up to $3.5^{\circ} \mathrm{C}$ by the end of this century.

Based on this forecast, Murayama predicts that the number of hay-fever sufferers in Japan will rise $40 \%$ by 2050 . "Global warming will continue to intensify what is already a serious health problem in Japan," he says.

Many agree with Murayama's findings. "It's common sense," says Atsushi Ueda, an allergy specialist at Kumamoto University. Ueda adds that higher levels of carbon dioxide and diesel-exhaust particles can also worsen the body's response to pollen.

But other scientists argue that economic factors may be to blame. Yoko Fukuda, a researcher at Japan's Forestry Agency, points to the decline in domestic forest industries, which has left the cedar and cypress plantations unmaintained. "Such neglect has allowed the trees to mature to their prime pollen-producing age," he explains.

To comfort the hoards of sufferers, the Forest Tree Breeding Center is working on a plan to replace all the offending trees with pollen-free cypress and cedar. But this could take decades, and political support is still uncertain, says project leader Makoto Takahashi.

Despite the difficulties, scientists are determined to find ways to improve the situation - and to ease their own symptoms. Murayama's research was first motivated by his wife's hay fever. But after conducting studies in the forests, he has experienced the problem first hand. "I can now tell you all about the miseries of pollen allergies," he says.

\section{Corporate culture nets big bucks for university heads}

\section{Emma Marris, Washington}

A growing tendency for US universities to embrace private-sector attitudes is undermining the system, say many of the country's professors. Many campus presidents are now paid as if they were corporate chief executives - and some academics say that this is rewarding the wrong type of leadership.

A recent report has revealed that salaries for university presidents have shot up over the past decade, whereas pay packets for professors have barely kept pace with inflation (see graph, right).

John Curtis, director of research at the American Association of University Professors (AAUP) in Washington DC, discovered the extent of the disparity when he compared figures from the AAUP's annual salary survey with presidential salary data from the College and University Professional Association for Human Resources.

The average professor at a $\mathrm{PhD}$-granting university earned about $\$ 100,700$ in 2003-04, he says, whereas the average president got $\$ 270,000$. The difference is especially pronounced at private institutions, he adds.
Salaries at US PhD-granting universities

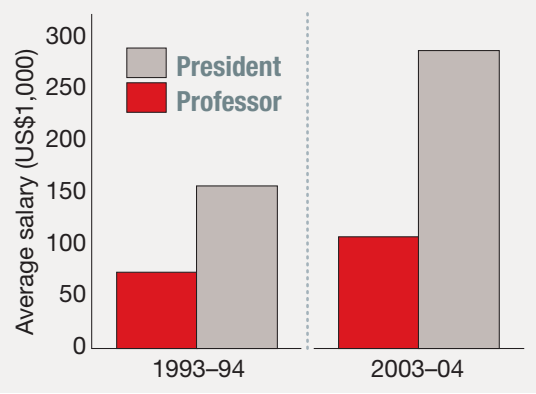

Johns Hopkins University's president, William Brody, was the most highly paid president in 2003, according to a survey in The Chronicle of Higher Education, earning just over $\$ 590,000$.

Curtis sees the growing gap as a "move towards the more corporate style of management", with universities paying high salaries for ruthless cost-cutting leadership. This is the wrong model, he argues, because universities are not run to make shareholders rich, but to educate students and benefit society.

Raymond Pierotti, a biologist at the
University of Kansas in Lawrence, has been following the salary trends for several years. He says that a dip in federal and state funding is forcing universities to act more like companies. He worries that the high salaries will attract "people who are willing to sell out what a university is supposed to stand for because they are more motivated by money".

But others say that the wages are fair compensation for an increasingly tough job. "The demands of the job are expanding," says Melanie Corrigan, a policy analyst at the American Council on Education in Washington DC. "A president is a cross between a chief executive of a large corporation and a small-city mayor."

Pierotti says that the trend won't be reversed unless there is an influx of cash from government sources. But this may be far off - state and federal budgets are under pressure and are likely to remain tight for the foreseeable future. Meanwhile, Pierotti warns that the bottom line is beginning to affect professors as well. "Faculty members are assessed not only on the quality of their teaching or even their research, but on how fundable their research is," he says. 